\title{
Determination of five flavonoids in different parts of Fordia cauliflora by ultra performance liquid chromatography/triple-quadrupole mass spectrometry and chemical comparison with the root of Millettia pulchra var. laxior
}

Lanlan Fan ${ }^{1}$, Yazhou Zhang ${ }^{1}$, Renbin Huang ${ }^{3}$, Shanding Qin ${ }^{1}$, Tao Yi ${ }^{2}$, Feng X X ${ }^{4}$, Yina Tang ${ }^{2}$, Xiaosheng Qu', Hubiao Chen ${ }^{2^{*}}$ and Jianhua Miao ${ }^{1^{*}}$

\begin{abstract}
Background: The root of Fordia cauliflora Hemsl (FC) has long been used in southern China for the treatment of rheumatism, bruises, dementia in children, and valetudinarianism. However, sometimes it is mixed with other parts. And it has always been confused with the root of Millettia pulchra (Benth.) Kurz var. laxior (Dunn) Z. Wei (MP) by the local people. The chemical differences between the two ethnic drugs are not clear until now. The aim of this study is to develop a precise and accurate method to characterize and quantify multiple chemical components of $\mathrm{FC}$, which is helpful for the quality evaluation and identification of FC.

Results: A method coupling ultra performance liquid chromatography (UPLC) with triple-quadrupole mass spectrometry (QqQ-MS) was first developed for simultaneous determination of five flavonoids in different parts of FC and the root of MP, based on a UPLC-diode array detection (DAD) fingerprint method. All calibration curves showed good linearity $\left(R^{2}>0.99\right)$ within test ranges. The overall LOD and LOQ were lower than $2.5 \mathrm{ng} / \mathrm{mL}$ and $5.0 \mathrm{ng} / \mathrm{mL}$, respectively. The RSDs for intra- and inter-day of five analytes were less than $2.83 \%$ and $3.04 \%$, respectively. Recovery studies for the quantified compounds were found to be within the range 93.6-99.8\% with RSD less than $5.73 \%$. The results suggest that the root, traditionally used medicinal part, yields the highest flavanoid content in FC. Pachycarin A, 3', $4^{\prime}$-dimethoxy $\left(2^{\prime \prime}, 3^{\prime \prime}: 7,8\right)$ furanoflavone, karanjachromene and isoderricin A can be used to differentiate between FC and MP samples.
\end{abstract}

Conclusions: The present method is specific, precise and reliable, and is suitable for characterizing and quantifying multiple chemical components of FC.

Keywords: Fordia cauliflora, Millettia pulchra var. laxior, Fordiae Cauliforae Radix, Millettiae Pulchrae Radix, UPLC-QqQ-MS, UPLC-DAD, Determination, Identification, Ethnic drug

\footnotetext{
* Correspondence: hbchen@hkbu.edu.hk; mjh1962@vip.163.com

${ }^{2}$ School of Chinese Medicine, Hong Kong Baptist University, Hong Kong Special Administrative Region, China

${ }^{1}$ Guangxi Botanical Garden of Medicinal Plants, Nanning, China

Full list of author information is available at the end of the article
} 


\section{Background}

The root of Fordia cauliflora Hemsl (FC), Fordiae cauliflorae Radix, from the Leguminosae family[1-3], known as "Shuiluosan", has been used for the treatment of rheumatism, bruises, dementia in children, valetudinarianism and so on by the Zhuang and Yao people in Guangxi Zhuang Autonomous Region of China for over five hundred years. Pharmacological studies have shown that it improves shortand long-term memory and acquired memory disorder of mice $[4,5]$, and that it has anti-aging [6], anti-inflammatory [7], hepato-protective [8], and antioxidative [8] effects. However, the root is difficult to obtain than other parts, such as stem and leaves, and thus, sometimes they have been mixed with other parts.

The root of Millettia pulchra (Benth.) Kurz var. laxior (Dunn) Z. Wei (MP), Millettiae Pulchrae Radix, known as "Daluosan" [3,9], is also used for the treatment of rheumatism, bruises, dementia in children, valetudinarianism and so on $[3,10]$. The local people always confused FC with MP, because they share similar therapeutic functions and are both called "Luosan" in the locality. By the way, the major active compounds of FC and MP are flavonoids, such as furonaflavones, pyranoflavones and chalcones [9-11]. The only reported major constituent in common, namely karanjin, possesses potential pesticidal, antiinflammatory effects [11] et al. However, the chemical composition differences between FC and MP are still not clear. Therefore, it is necessary to develop an effective method to evaluate FC, and distinguish it from MP.

The modern technologies, UV [12], TLC [13,14], TLC-FI [15], and HPLC [16,17], have been utilized for the quality control of FC and MP. However, no fingerprint analysis of the two medicines has been reported yet. Nowadays, ultra-performance liquid chromatography coupled with mass spectrometry technology has been found to be a superior method for the quality evaluation of herbal medicines due to the high resolution and detection sensitivity [18-21]. The compounds in a mixture can be efficiently separated by UPLC, and can be characterized by MS. Accordingly, in the present study, an ultra performance liquid chromatography coupled with triplequadrupole mass spectrometry (UPLC-QqQ-MS) was developed, based on a UPLC-diode array detector (DAD) fingerprint method, for the determination of five key flavonoids in three different parts of FC samples from different geological areas, and then compared with the root of MP. The validation results revealed that the developed method is highly efficient and reliable, and hence suitable for quantitative analysis and identification of FC samples.

\section{Experimental}

Materials, chemicals and reagents

Fifteen samples of Fordia cauliflora Hemsl (FC1-FC15) and two samples of Millettia pulchra (Benth.) Kurz var. laxior (Dunn) Z. Wei (MP1-MP2) were collected from Guangxi Zhuang Autonomous Region of China. FC1-FC3 were collected from Guangxi Botanical Garden of Medicinal Plants, MP1 and MP2 were cultivated in Lingshan, and the rest of the samples were obtained from the wild. Identity of the samples was confirmed by the authors, and voucher specimens were deposited in the School of Chinese Medicine, Hong Kong Baptist University.

Pachycarin A, 3',4' -dimethoxy $\left(2^{\prime \prime}, 33^{\prime \prime}: 7,8\right)$ furanoflavone, karanjin, karanjachromene and isoderricin A were separated and purified in our laboratory (98\%, determined by HPLC). The chemical structures of the five compounds are shown in Figure 1.

Analytical grade methanol and chromatographic grade acetonitrile were purchased from Labscan (Bangkok, Thailand), and chromatographic grade formic acid was purchased from Fluka (Buchs, Switzerland). Deionized water was obtained from a Milli-Q water purification system (Millipore, Bedford, MA, USA).

\section{Preparation of sample solutions}

All samples were ground into powder, and passed through a 40 -mesh sieve. The sample powder $(0.25 \mathrm{~g})$ was extracted with $10 \mathrm{~mL}$ of methanol by means of ultrasonication at room temperature for $0.5 \mathrm{~h}$. These operations were repeated once, and the residue was washed with $4 \mathrm{~mL}$ of methanol. Total extracts were combined in a $25-\mathrm{mL}$ volumetric flask, which was filled to the calibration mark with extraction solvent. The extracts were then filtered through a syringe filter $(0.22 \mu \mathrm{m}$, Alltech, Beerfield, IL, USA) before used.

\section{Ultra performance liquid chromatography-diode array detector (UPLC-DAD) fingerprint analysis}

A Waters Acquity ${ }^{\text {TM }}$ ultra-performance liquid chromatography (UPLC) system (Waters Corp., Milford, USA) consisting of a binary pump, autosampler, thermostated column compartment and diode array detector (DAD), was used for fingerprint analysis. The chromatographic separation was carried out on a Waters ACQUITY UPLC ${ }^{\bullet}$ HSS column $(100 \times 2.1 \mathrm{~mm}$ i.d., $1.8 \mu \mathrm{m}$, Waters Corp. $)$ with a VanGuard ${ }^{\mathrm{Tm}}$ pre-column (HSS, $\mathrm{C}_{18}, 1.8 \mu \mathrm{m}, 2.1 \mathrm{~mm} \times 5 \mathrm{~mm}$ ). The mobile phase consisted of $0.1 \%$ formic acid (FA) in water (A) and $0.1 \%$ FA in acetonitrile (B) using a gradient program of $25-40 \%$ (B) in $0-4 \mathrm{~min}, 40-66 \%$ in $4-23 \mathrm{~min}$. The solvent flow rate was $0.35 \mathrm{~mL} / \mathrm{min}$, the column temperature was set to $40^{\circ} \mathrm{C}$ and the detection wavelength was $258 \mathrm{~nm}$. The filter samples were diluted 10 times with methanol. An aliquot of $5 \mu \mathrm{L}$ solution was injected for analysis.

\section{Ultra performance liquid chromatography-triple quadrupole mass spectrometry (UPLC-QqQ-MS)}

An Agilent 6460 Triple Quadrupole LC/MS system (Agilent Technologies, the USA) was used. The chromatographic 
<smiles>COc1ccc(-c2oc3c(ccc4occc43)c(=O)c2OC)cc1OC</smiles><smiles></smiles>

3',4'-dimethoxy(2",3": 7,8) furanoflavone (2)<smiles>COc1c(-c2ccccc2)oc2c(ccc3occc32)c1=O</smiles>

Karanjin (3)<smiles>COc1c(-c2ccccc2)oc2c3c(ccc2c1=O)OC(C)(C)C=C3</smiles>

Karanjachromene (4)<smiles>COc1ccc2c(c1CC=C(C)C)OC(c1ccccc1)CC2=O</smiles>

Isoderricin A (5)

Figure 1 Chemical structures of the five analytes.

separation was carried out on a Waters ACQUITY UPLC ${ }^{\bullet}$ HSS column $(100 \times 2.1 \mathrm{~mm}$ i.d., $1.8 \mu \mathrm{m}$, Waters Corp. $)$ with a VanGuard ${ }^{\mathrm{mm}}$ pre-column (HSS, $\mathrm{C}_{18}, 1.8 \mu \mathrm{m}, 2.1 \mathrm{~mm} \times$ $5 \mathrm{~mm}$ ). The mobile phase consisted of $0.1 \% \mathrm{FA}$ in water (A) and $0.1 \%$ FA in acetonitrile (B) using a gradient program of $35-85 \%$ (B) in $0-11 \mathrm{~min}$. The solvent flow rate was $0.35 \mathrm{~mL} / \mathrm{min}$, the column temperature was set to $40^{\circ} \mathrm{C}$. The filtered samples were diluted 20 times with methanol. An aliquot of $1.0 \mu \mathrm{L}$ solution was injected for analysis.

The column effluent was directly introduced into a triple quadrupole mass detector operated in a positive ESI mode. Nitrogen was used as both the drying and sheath gases and the collision gas. The ESI source parameters were as follows: gas temperature, $300^{\circ} \mathrm{C}$; gas flow, $7 \mathrm{~L} / \mathrm{min}$; nebulizer gas pressure, $45 \mathrm{psi}$; sheath gas temperature, $350^{\circ} \mathrm{C}$; sheath gas flow, $8 \mathrm{~L} / \mathrm{min}$; capillary voltage, $3.5 \mathrm{kV}$. The fragmentor voltage was $130 \mathrm{~V}$ for all compounds. The collision energy was selected for each compound individually, and ranged from 21 to $81 \mathrm{eV}$. Samples were analyzed by UPLC-QqQ-MS in the multiple reaction monitoring (MRM) mode to maximize sensitivity. Characteristic transitions (precursor ion $\rightarrow$ product ion) are shown in Table 1. Data analysis was performed with Agilent Mass
Hunter Qualitative Analysis B.04.00 Software (Agilent Technologies, the USA).

\section{Method validation}

Each standard was dissolved in methanol and then mixed as stock solution at the concentration of $1 \mathrm{mg} / \mathrm{mL}$, and stored in the refrigerator. The working solutions were prepared by appropriate dilution, and the resulting concentration ranges are listed in Table 2. The calibration curve was established by plotting the peak area against the concentrations of the standards with linear regression analysis. The limit of detection (LOD) and limit of quantification (LOQ) for each analyte were determined at an $\mathrm{S} / \mathrm{N}$ of about 3 and 10 , respectively. Intra- and inter-day variations were chosen to determine the precision of the developed method. For the intra-day variation test, three levels of the mixed standards solution was analyzed for six replicates $(n=6)$ within one day, while for the inter-day variations test, the three levels was examined in duplicates for consecutive 3 days $(n=6)$. The repeatability of the method was determined by analyzing one FC samples for six replicates and represented as RSD. The recovery was performed by adding three levels of known amount of

Table 1 MRM transition parameters of five analytes (Positive ESI mode)

\begin{tabular}{|c|c|c|c|c|c|}
\hline Peak & $R \mathrm{t}$ (min) & Compounds & MRM transition & Fragmentation (V) & Collision energy $(\mathrm{eV})$ \\
\hline \multirow[t]{2}{*}{1.} & 5.04 & Pachycarin A & $353>323$ & 130 & 29 \\
\hline & & & $353>295$ & 130 & 33 \\
\hline 2. & 5.60 & $3^{\prime}, 4^{\prime}$-dimethoxy $\left(2^{\prime \prime}, 3^{\prime \prime}: 7,8\right)$ furanoflavones & $323>293$ & 130 & 33 \\
\hline \multirow[t]{2}{*}{3.} & 6.17 & Karanjin & $293>277$ & 130 & 33 \\
\hline & & & $293>89$ & 130 & 81 \\
\hline \multirow[t]{2}{*}{4.} & 8.46 & Karanjachromene & $335>305$ & 130 & 29 \\
\hline & & & $335>187$ & 130 & 49 \\
\hline \multirow[t]{2}{*}{5.} & 9.66 & Isoderricin A & $323>105$ & 130 & 25 \\
\hline & & & $323>163$ & 130 & 21 \\
\hline
\end{tabular}


Table 2 Linearity curves, LOD and LOQ for five analytes

\begin{tabular}{llllll}
\hline Compounds & Linear equations & Range $(\mathbf{n g} / \mathbf{m L})$ & $\boldsymbol{R}^{\mathbf{2}}$ & LOD $(\mathbf{n g} / \mathbf{m L})$ & $\mathbf{L O Q}(\mathbf{n g} / \mathbf{m L})$ \\
\hline Pachycarin A & $\mathrm{y}=768.5 x+7174.2$ & $2.5-2500$ & 0.9989 & 0.2 & 1.0 \\
\hline $3^{\prime}, 4^{\prime}$-dimethoxy $\left(2^{\prime \prime}, 3^{\prime \prime}: 7,8\right)$ furanoflavones & $\mathrm{y}=15702.1 x+161577.2$ & $2.5-2500$ & 0.9991 & 0.2 & 1.0 \\
\hline Karanjin & $\mathrm{y}=5434.7 x+95172.3$ & $2.5-2500$ & 0.9985 & 0.1 & 0.5 \\
\hline Karanjachromene & $\mathrm{y}=7224.7 x+37031.0$ & $2.5-2500$ & 0.9996 & 0.1 & 0.5 \\
\hline Isoderricin A & $\mathrm{y}=1832.1 x+64281.6$ & $5.0-10000$ & 0.9996 & 2.5 & 5.0 \\
\hline
\end{tabular}

stock solution into a certain amount of FC samples. Two replicates of each sample were extracted and analyzed.

\section{Results and discussion}

\section{Optimization of analysis conditions}

The extraction solvents initially tested were methanol, $80 \%$ methanol, $50 \%$ methanol and ethanol. The results revealed that extraction with absolute methanol produced the highest yield for the desired analytes. Thus, methanol was chosen as the extraction solvent. Extraction times and cycles were further optimized, and the results demonstrated that exhaustive extraction could be achieved when $0.2 \mathrm{~g}$ of FC powder was extracted with $10 \mathrm{~mL}$ of methanol with two sonication cycles of $0.5 \mathrm{~h}$.

The conditions for chromatographic analysis including the type of column and column temperature were optimized. Mobile phase gradients were compared on an HSS $\mathrm{C}_{18}$ column and a BEH $\mathrm{C}_{18}$ column at different temperatures. The results showed that satisfactory separation could best be obtained by eluting FC samples on an HSS $\mathrm{C}_{18}$ column at $40^{\circ} \mathrm{C}$ using a linear gradient of $0.1 \%$ formic acid (FA) in acetonitrile and $0.1 \% \mathrm{FA}$ in water within $11 \mathrm{~min}$.

A wavelength of $258 \mathrm{~nm}$ was chosen to monitor the constituents in UPLC-DAD after comparing the chromatograms of the FC and MP samples recorded at wavelengths within 190-500 nm. It was found that the analysis time of UPLC-QqQ-MS could be shortened from $22 \mathrm{~min}$ to 11 min without loss of accuracy; thus the shorter period was chosen to save time and solvent.

\section{UPLC-DAD fingerprint}

The representative UPLC-DAD fingerprint chromatograms of roots, stems and leaves of Fordia cauliflora (FC), and roots of Millettia pulchra (Benth.) Kurz var. laxior (Dunn) Z. Wei (MP) are shown in Figure 2. This is the first report about the fingerprint of FC and MP. With respect to FC, pachycarin A, 3',4'-dimethoxy $\left(2^{\prime \prime}, 3^{\prime \prime}: 7,8\right)$ furanoflavone, karanjin, karanjachromene and isoderricin $\mathrm{A}$ are the major peaks in the roots. The chemical composition of the stems was similar to the roots, while some peaks were absent in the leaves, such as isoderricin A. However, fewer peaks were detected in the roots of
MP. Karanjin showed the highest peak in MP, and was seen in both FC and MP.

\section{MS characterization of the five flavonoids}

The positive ionization mode was selected for quantification tests. To enhance the selectivity and sensitivity of the MS detection, multiple reaction monitoring (MRM) [18] was employed. To determine the best MRM parameters for the five flavonoids, pachycarin A (1), 3', $4^{\prime}-$ dimethoxy $\left(2^{\prime \prime}, 3^{\prime \prime}: 7,8\right)$ furano flavone (2), karanjin (3), karanjachromene (4) and isoderricin A (5), their MS and MS/MS spectra were measured by the infusion of each flavone, one by one.

Both the precursor ions $\left([\mathrm{M}+\mathrm{H}]^{+}\right)$of (2) and (5), $m / z$ 323 , were selected as the precursor ions. However, the product ion of (2) was $m / z 293$, while for (5) was $\mathrm{m} / \mathrm{z}$ 105 and 163. The details are listed in Table 1.

In order to promote the formation of quasi-molecular ions $[\mathrm{M}+\mathrm{H}]^{+}$in MS analysis, $0.1 \%$ formic acid was used in the mobile phase.

\section{Method validation of UPLC-QqQ-MS Specificity}

The representative MRM chromatograms of the three parts of F. cauliflora (FC) and root of M. pulchra (Benth.) Kurz var. laxior (Dunn) Z. Wei (MP) are shown in Figure 3. UPLC-QqQ-MS in MRM mode could clearly separate and identify the five compounds, thus saving analysis time. The retention times of pachycarin $\mathrm{A}, 3^{\prime}, 4^{\prime}-$ dimethoxy $\left(2^{\prime \prime}, 3^{\prime \prime}: 7,8\right)$ furanoflavone, karanjin, karanjachromene and isoderricin A were 5.04, 5.60, 6.17, 8.46 and 9.66 min, respectively. All the peaks of the analytes were detected with excellent resolution.

\section{Linearity}

The regression equations, correlation coefficients, test ranges, LODs and LOQs are shown in Table 2. The results showed that there was excellent correlation between the ratio of peak area and concentration for each compound within the test ranges. The LODs were $0.2,0.2,0.1,0.1$ and $2.5 \mathrm{ng} / \mathrm{mL}$ for pachycarin A, $3^{\prime}, 4^{\prime}$-dimethoxy $\left(2^{\prime \prime}, 3^{\prime \prime}: 7,8\right)$ furanoflavone, karanjin, karanjachromene and isoderricin $\mathrm{A}$, and the LOQs were 1.0, 1.0, 0.5, 0.5 and $5.0 \mathrm{ng} / \mathrm{mL}$, 


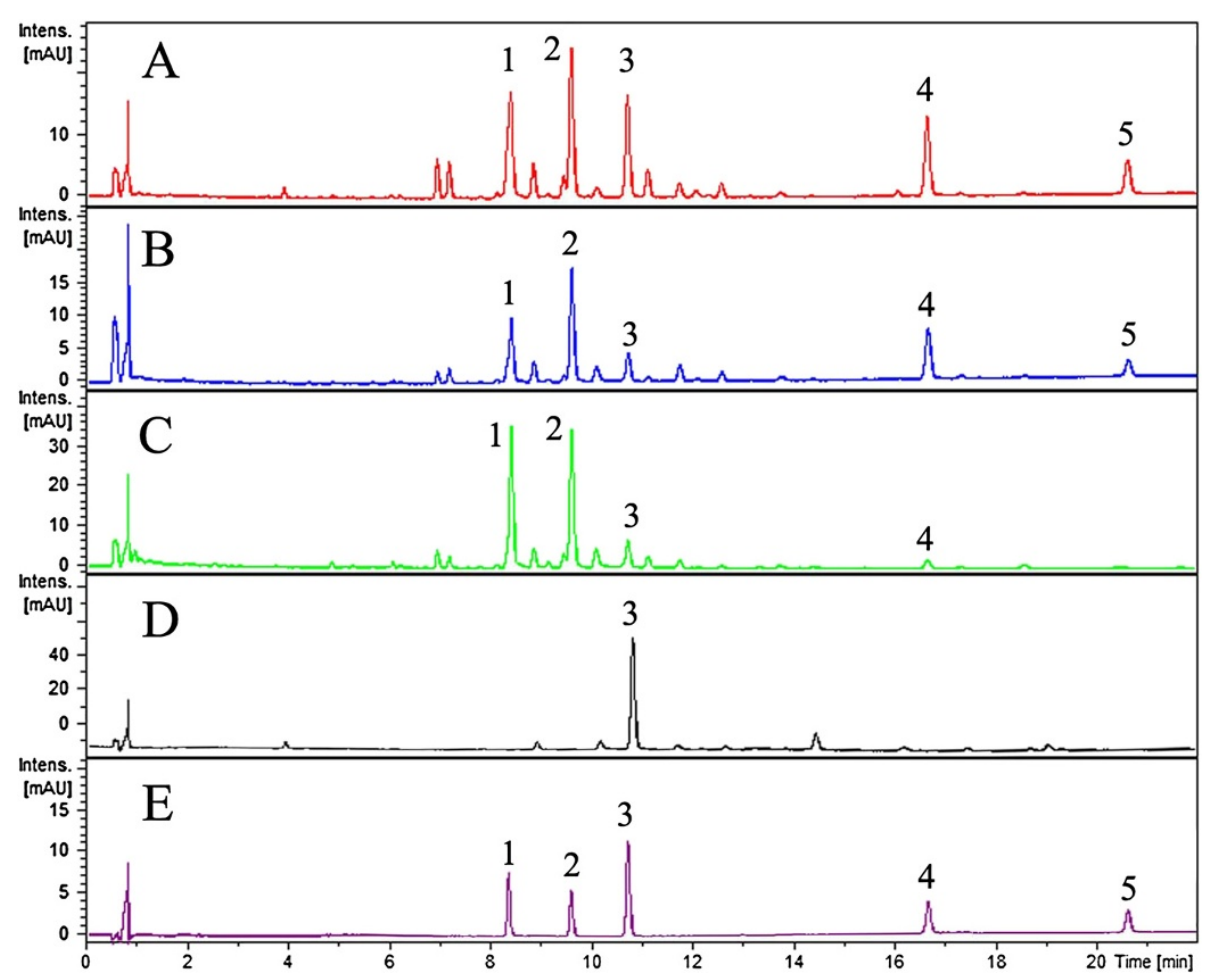

Figure 2 Representative UPLC-DAD fingerprint chromatograms of roots of Fordia cauliflora (A), stems of $F$. cauliflora (B), leaves of F. cauliflora (C), roots of Millettia pulchra var. laxior (D), and reference compounds (E). Peak identification: 1. Pachycarin A, 2. 3',4'-dimethoxy(2",3':7,8) furanoflavone, 3. Karanjin, 4. Karanjachromene, and 5. Isoderricin A.

respectively, indicating that this method is sensitive for the quantitative evaluation of the five compounds.

\section{Precision, repeatability and extraction recovery}

The assay precision results are shown in Table 3. The intra- and inter-day precisions (RSD) of these analytes were all less than $2.83 \%$ and $3.04 \%$, respectively. The repeatabilities (RSD, $n=3$ ) of the five compounds were all less than $3.14 \%$. The mean extraction recoveries and RSD of pachycarin A were $99.8 \%$ and $1.27 \%$, of $3^{\prime}, 4^{\prime}-$ dimethoxy $\left(2^{\prime \prime}, 3^{\prime \prime}: 7,8\right)$ furanoflavone were $93.6 \%$ and $4.80 \%$, of karanjin were $97.1 \%$ and $5.29 \%$, of karanjachromene were $95.4 \%$ and $5.73 \%$, and of isoderricin A were $95.5 \%$ and $4.68 \%$. The results demonstrated that the values were all within the acceptable range, and that the method was accurate and precise.

\section{Sample analysis}

The developed UPLC-QqQ-MS method was employed for the determination of five flavonoids in three different parts (roots, stems and leaves) of FC samples from five locations, and the roots of MP samples. Typical MRM chromatograms are shown in Figure 3. Table 4 summarizes the contents of the investigated compounds. Several conclusions can be drawn from our results:

First of all, the content of each compound varied in different parts of FC, and has their own distribution characteristics. The total content ranges of the five compounds were $8.54-14.28,0.49-3.07$, and $1.02-3.54 \mathrm{mg} / \mathrm{g}$ for roots, stems and leaves of FC samples, respectively. The contents of pachycarin A, karanjin, karanjachromene and isoderricin A were highest in the roots, while the content of $3^{\prime}, 4^{\prime}$-dimethoxy $\left(2^{\prime \prime}, 3^{\prime \prime}: 7,8\right)$ furanoflavone varied; indeed, sometimes it could not be detected. Isoderricin A could not be detected in the leaves, even though it was obtained in the highest content among the five compounds. So the root yields the highest flavanoid content, which is in accordance with the fact that the root is traditionally used for medicinal purposes.

Secondly, only karanjin was detected in both MP and FC, and the other four flavonoids were absent in MP. The contents of karanjin in the two MP samples were 0.50 and $0.65 \mathrm{mg} / \mathrm{g}$, respectively. Thus the other four compounds, pachycarin A, 3',4'-dimethoxy $\left(2^{\prime \prime}, 3^{\prime \prime}: 7,8\right)$ furanoflavone, karanjachromene and isoderricin $\mathrm{A}$, can be used to distinguish the two medicinal plants. 

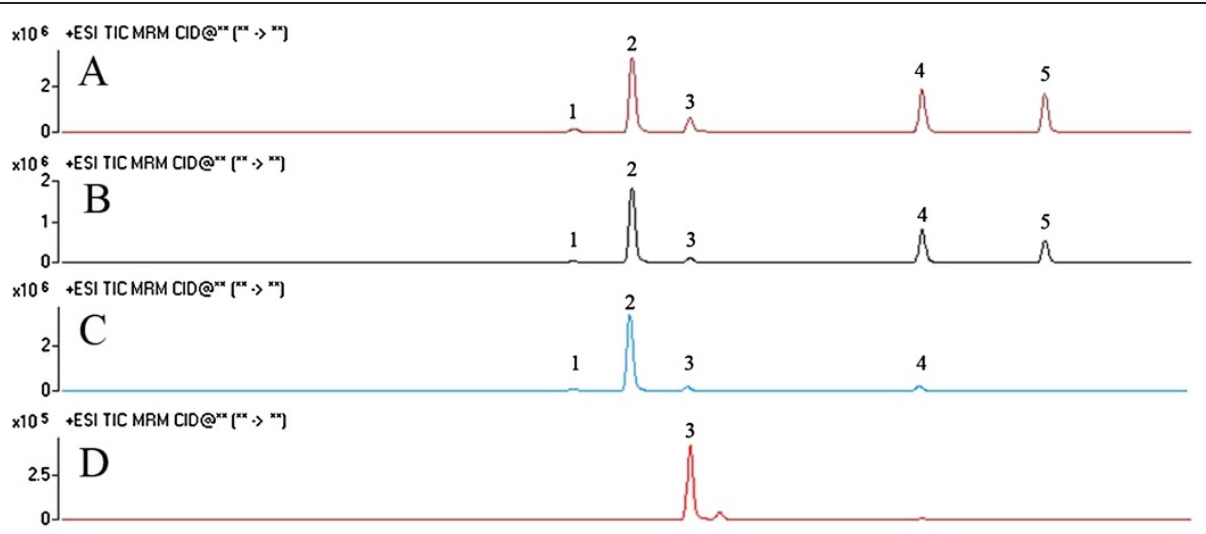

$\times 10^{4}+$ ESI MRM Frag=130.0v C10@29.0 (353.0000 $\left.\rightarrow 323.1016\right)$

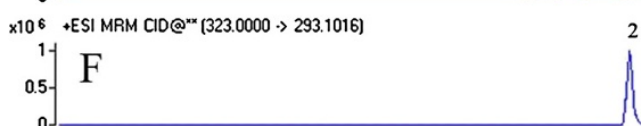

$x 10^{5}+$ ESI MRM FIag=130.0V CID@33.0 (293.0000 $\left.>277.1016\right)$<smiles>[Li][Ca]</smiles>

$\times 10^{6}+$ ESI MRM Frag=130.0 CID@29.0 (335.0000 • 305.1016)

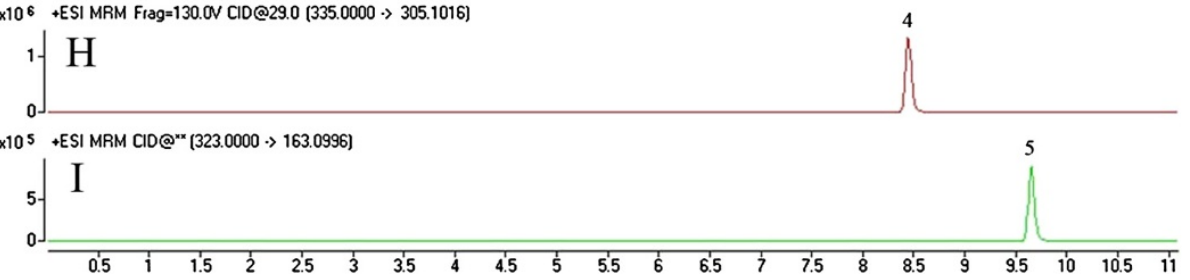

Figure 3 Representative MRM chromatograms of roots of $F$. cauliflora (A), stems of $F$. cauliflora (B), leaves of $F$. cauliflora (C), roots of M. pulchra var. laxior (D), and the five analytes (E-I) by UPLC-QqQ-MS. Peak identification: 1. Pachycarin A, 2. $3^{\prime}, 4^{\prime}-\operatorname{dimethoxy}\left(2^{\prime \prime}, 3^{\prime \prime}: 7,8\right)$ furanoflavone, 3. Karanjin, 4. Karanjachromene, and 5. Isoderricin A.

Table 3 Intra- and Inter-day variation of the investigated compounds

\begin{tabular}{|c|c|c|c|}
\hline Compounds & $\begin{array}{l}\text { Concentration } \\
\text { (ng/mL) }\end{array}$ & $\begin{array}{l}\text { Intra-day RSD } \\
(\%, \mathrm{n}=6)\end{array}$ & $\begin{array}{l}\text { Inter-day RSD } \\
(\%, n=6)\end{array}$ \\
\hline \multirow[t]{3}{*}{ Pachycarin A } & 1000 & 1.60 & 1.67 \\
\hline & 500 & 2.13 & 2.42 \\
\hline & 250 & 1.89 & 3.04 \\
\hline \multirow[t]{3}{*}{$3^{\prime}, 4^{\prime}$-dimethoxy $\left(2^{\prime \prime}, 3^{\prime \prime}: 7,8\right)$ furanoflavones } & 1000 & 1.81 & 2.97 \\
\hline & 500 & 2.26 & 2.83 \\
\hline & 250 & 1.99 & 2.50 \\
\hline \multirow[t]{3}{*}{ Karanjin } & 1000 & 2.58 & 2.99 \\
\hline & 500 & 2.83 & 4.08 \\
\hline & 250 & 2.11 & 2.07 \\
\hline \multirow[t]{3}{*}{ Karanjachromene } & 1000 & 1.15 & 2.75 \\
\hline & 500 & 2.28 & 3.11 \\
\hline & 250 & 2.15 & 2.88 \\
\hline \multirow[t]{3}{*}{ Isoderricin A } & 1000 & 1.23 & 1.41 \\
\hline & 500 & 1.83 & 2.67 \\
\hline & 250 & 1.47 & 1.11 \\
\hline
\end{tabular}


Table 4 Contents of five compounds in the FC and MP samples

Species Code Used part Habitats Collection

Contents of five compounds ( $\mathrm{mg} / \mathrm{g}, \mathrm{n}=3$ )

\begin{tabular}{|c|c|c|c|c|c|c|c|c|c|c|}
\hline & & & & & ( & furanoflavone (2) & (2) & 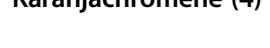 & 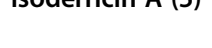 & \\
\hline \multirow[t]{15}{*}{ Fordia cauliflora } & FC1 & root & Nanning, Guangxi & 2011.8 .14 & $0.78 \pm 0.04$ & $1.57 \pm 0.03$ & $0.85 \pm 0.03$ & $1.61 \pm 0.05$ & $4.19 \pm 0.04$ & 9.00 \\
\hline & FC2 & stem & Nanning, Guangxi & 2011.8 .14 & $0.09 \pm 0.00$ & $0.88 \pm 0.01$ & $0.12 \pm 0.00$ & $0.71 \pm 0.02$ & $1.28 \pm 0.01$ & 3.08 \\
\hline & $\mathrm{FC3}$ & leaves & Nanning, Guangxi & 2011.8 .14 & $0.20 \pm 0.00$ & $1.60 \pm 0.03$ & $0.20 \pm 0.01$ & $0.18 \pm 0.01$ & ND & 2.18 \\
\hline & $\overline{F C 4}$ & root & Nanning, Guangxi & 2012.7 .12 & $2.69 \pm 0.05$ & $0.10 \pm 0.00$ & $2.16 \pm 0.04$ & $1.75 \pm 0.01$ & $3.14 \pm 0.03$ & 9.84 \\
\hline & FC5 & stem & Nanning, Guangxi & 2012.7.12 & $0.44 \pm 0.02$ & ND & $0.22 \pm 0.01$ & $0.33 \pm 0.01$ & $0.48 \pm 0.00$ & 1.47 \\
\hline & FC6 & leaves & Nanning, Guangxi & 2012.7 .12 & $1.99 \pm 0.08$ & $0.01 \pm 0.00$ & $0.36 \pm 0.01$ & $0.24 \pm 0.01$ & ND & 2.60 \\
\hline & FC7 & root & Wuming, Guangxi & 2012.7.12 & $0.45 \pm 0.02$ & $0.69 \pm 0.01$ & $1.90 \pm 0.06$ & $0.82 \pm 0.03$ & $4.68 \pm 0.04$ & 8.54 \\
\hline & FC8 & stem & Wuming, Guangxi & 2012.7.12 & $0.05 \pm 0.00$ & $0.20 \pm 0.01$ & $0.34 \pm 0.01$ & $0.27 \pm 0.01$ & $0.71 \pm 0.03$ & 1.57 \\
\hline & FC9 & leaves & Wuming, Guangxi & 2012.7 .12 & $0.18 \pm 0.01$ & $1.51 \pm 0.02$ & ND & $0.22 \pm 0.01$ & ND & 1.91 \\
\hline & FC10 & root & Pingle, Guangxi & 2012.7.10 & $1.46 \pm 0.05$ & $1.32 \pm 0.03$ & $2.32 \pm 0.04$ & $1.58 \pm 0.03$ & $1.17 \pm 0.03$ & 7.85 \\
\hline & FC11 & stem & Pingle, Guangxi & 2012.7 .10 & $0.08 \pm 0.00$ & $0.12 \pm 0.00$ & $0.04 \pm 0.00$ & $0.11 \pm 0$ & $0.15 \pm 0.01$ & 0.50 \\
\hline & $\mathrm{FC} 12$ & leaves & Pingle, Guangxi & 2012.7.10 & $0.55 \pm 0.01$ & $0.40 \pm 0.01$ & $0.01 \pm 0.00$ & $0.06 \pm 0.00$ & ND & 1.02 \\
\hline & FC13 & root & Pingxiang, Guangxi & 2012.7.12 & $2.16 \pm 0.06$ & $0.06 \pm 0.01$ & $2.49 \pm 0.05$ & $1.66 \pm 0.03$ & $7.91 \pm 0.15$ & 14.28 \\
\hline & FC14 & stem & Pingxiang, Guangxi & 2012.7 .12 & $0.17 \pm 0.01$ & $\mathrm{ND}$ & $0.12 \pm 0.01$ & $0.14 \pm 0$ & $0.38 \pm 0.01$ & 0.81 \\
\hline & FC15 & leaves & Pingxiang, Guangxi & 2012.7.12 & $2.87 \pm 0.03$ & ND & $0.39 \pm 0.01$ & $0.28 \pm 0.01$ & ND & 3.54 \\
\hline \multirow[t]{2}{*}{ Millettia pulchra var. laxior } & MP1 & root & Lingshan, Guangxi & 2012.7 .12 & ND & ND & $0.65 \pm 0.01$ & ND & ND & 0.65 \\
\hline & MP2 & root & Lingshan, Guangxi & 2012.7.12 & ND & ND & $0.50 \pm 0.01$ & ND & ND & 0.50 \\
\hline
\end{tabular}

ND Not detected. 
Thirdly, the content ranges of pachycarin A, 3',4'dimethoxy $\left(2^{\prime \prime}, 3^{\prime \prime}: 7,8\right)$ furanoflavone, karanjin, karanjachromene and isoderricin A in the roots of FC samples from different habitats were $0.45-2.69,0.10-1.57,0.85$ $2.49,0.82-1.75$, and $1.17-7.91 \mathrm{mg} / \mathrm{g}$, respectively. However, the contents of each compound seem to have no relation with the distribution area. Just to mention, there is only one report regarding the HPLC quantification of karanjin and 3'-methoxykaranjin in FC and MP [16]. Therefore this report is the first one to simultaneously quantify pachycarin $\mathrm{A}, 3^{\prime}, 4^{\prime}$ - $\operatorname{dimethoxy}\left(2^{\prime \prime}, 3^{\prime \prime}: 7,8\right)$ furano flavone, karanjachromene and isoderricin $\mathrm{A}$ in $\mathrm{FC}$ and MP. However, our results show that the content ranges of karanjin from FC and MP are $0.85-2.49 \mathrm{mg} / \mathrm{g}$ and $0.50-0.65 \mathrm{mg} / \mathrm{g}$, respectively, as mentioned above. These data are lower than those reported, in which the content of karanjin from four FC samples was 2.13-4.54 mg/g, and from MP samples was $0.61-1.22 \mathrm{mg} / \mathrm{g}$. This may be due to different harvesting times and habitats.

As we know, flavonoids are the major constituents of FC and MP, and play very important roles in the pharmaceutical activities of FC and MP, such as karanjin as mentioned before, and karanjachromene, which possesses significant antioxidant activity [22]. Our results show that the root yields the highest flavanoid content, so it is reasonable that the medicinal part is the root. The results also suggest that pachycarin A, 3',4'dimethoxy $\left(2^{\prime \prime}, 3^{\prime \prime}: 7,8\right)$ furanoflavone, karanjachromene and isoderricin A can be used to distinguish FC from MP samples.

\section{Conclusions}

A novel UPLC-QqQ-MS method was first developed for the simultaneous analysis of five flavonoids in the root, stem and leaves of Fordia cauliflora (FC) based on a first reported UPLC-DAD fingerprint method. The method was also applied to the root of Millettia pulchra var. laxior (MP) to compare their chemical characteristics. The present hyphenation procedure is highly efficient and reliable, and hence suitable for quantitative analysis of FC samples. The determination results show the root of FC has the highest flavonoid content, and suggest that pachycarin A, 3',4'dimethoxy $\left(2^{\prime \prime}, 3^{\prime \prime}: 7,8\right)$ furanoflavone, karanjachromene and isoderricin $\mathrm{A}$, can be used for the identification of $\mathrm{FC}$ and MP samples.

\section{Abbreviations}

UPLC: Ultra performance liquid chromatography; DAD: Diode array detector QqQ-MS: Triple-quadrupole mass spectrometry.

\section{Competing interests}

The authors declare that they have no competing interests.

\section{Authors' contributions}

HBC and JHM initiated and all authors designed the study. The sample extraction was conduct by LLF and YZZ. The method developments were conducted by LLF who drafted the manuscript. All authors contributed to data analysis, read and approved the final manuscript.

\section{Acknowledgements}

This research was financially supported by the Health Department of Guangxi province (Zhong2010111, Z2010175), and Guangxi Administration of Traditional Chinese Medicine (GZKZ1131). The authors would like to thank Bin Dai at Guangxi Institute of Minority Nationality Medicine and Pharmacology for providing the plant photos of FC and MP.

\section{Author details}

'Guangxi Botanical Garden of Medicinal Plants, Nanning, China. ${ }^{2}$ School of Chinese Medicine, Hong Kong Baptist University, Hong Kong Special Administrative Region, China. ${ }^{3}$ School of Pharmaceutical Science, Guangxi Medical University, Nanning, China. ${ }^{4}$ School of Pharmaceutical Sciences, Peking University, Beijing, China.

Received: 17 April 2013 Accepted: 10 July 2013

Published: 19 July 2013

\section{References}

1. The Health Department of Guangxi: Guangxi Bencao compiled. Nanning: Guangxi people's Publishing House; 1974:1622.

2. Liang QC, Zhong M: Chinese Zhuang Medicine. Nanning: Guangxi Nationalities Publishing House; 2005:499.

3. Dai B: Chinese Modern Yao Medicine. Nanning: Guangxi Science and Technology Press; 2009:314-320.

4. Li ZQ: Study on effecte of Fordia cauliflora on mouse acquired memory disorder. Acad J Guangdong Coll Pharm 2002, 18:124-126.

5. Zhou Z, Wei QZ, Li ZQ, Chen BS, Wu ZQ, Dai B: Effect of Fordia cauliflora extracts on learning and memory ability. Guangxi J Tradit Chin Med 2003, 26:47-48.

6. Wei QZ, Wu ZQ, Zhou Z, Chen BS, Dai B: Researches on the Acuity, Toxicity and Antisenility of the extracts of Fordia cauliflora Hemsl. J Guangxi Tradit Chin Med Univ 2003, 6:37-40.

7. Tang ZQ, Chen BS, Zhou Z, Wu ZQ, Qiu CC, Chen SF, Dai B: Anti-inflammatory effect of various extracts of Fordia cauliflora. Chin J of Ethnomed and Ethnopharm 2003, 63:223-225.

8. Wu ZQ, Zhou Z, Wei QZ: Protective effects of Abstracts of Fordia Cauliflora Hemsl on bromobenzene-induced oxidative liver damage in mice and antioxidative capabil ity in old mice. Chin Pharmacol Bull 2004, 20:1221-1223.

9. The Health Department of Guangxi: Guangxi Herb Journal. Nanning: Guangxi People's Publishing House; 1963:74.

10. Jian J, Qing F, Zhang S, Huang J, Huang RB: The effect of 17-methoxyl-7hydroxy-benzene-furanchalcone isolated from Millettia pulchra on myocardial ischemia in vitro and in vivo. Planta Med 2012, 78:1324-1331.

11. Sapna WE, Sindhu Kanya TC, Mamatha AM, Lokesh BR, Appu Rao AG: Karanjin, a flavonoid inhibits lipoxygenases. In Proceedings of the National Academy of Science India. Mysore, India: CFTRl; 2007.

12. Chen SF, Dai B, Qiu CC, Liang GJ: Determination of total flavonoid content in Shuiluosan by UV Spectrophotometry. Chin $J$ of Ethnomed and Ethnopharm 2003, 60:35-37.

13. Dai B, Qiu CC, Chen SF, Zhou LN: Pharmacognostic studies on root of Fordia cauliflora. China Tradit Herb Drugs 2001, 32:456-459.

14. Dai XD, Qiu CC, Dai B, Yang DA: Chemical constituents analysis of Millettia pulchra var. laxior. Chin J of Ethnomed and Ethnopharm 2009, 20:9.

15. Yang DA, Yang LF, Ma SM: Determination of Karanjin in Radix of Fordia cauliflora by Thin Layer Chromatograph-Fluorescent Method. I Inf Tradit Chin Med 2006, 13:53-54

16. Dai XD, Dai B, Yang DA, Qiu CC: RP-HPLC Determination of Two Main Furanoflavone Constituents in Radix of Fordia cauliflora (Shuiluosan). Chin J Pharmaceut Anal 2003, 23:421-423.

17. Zhao YS, Zhu Y, Chen GB: RP- HPLC determination of Karanjin in Pongamia pinnata. Chin J Pharmaceut Anal 2010, 30:2287-2289.

18. Yi T, Tang YN, Zhang JY, Zhao ZZ, Yang ZJ, Chen HB: Characterization and determination of six flavonoids in the ethnomedicine "Dragon's Blood"by UPLC-PAD-MS. Chem Cent J 2012, 6:116-122.

19. Qian YY, Wang YL, Sa RN, Yan H, Pan XB, Yang YW, Sun YJ: Metabolic fingerprinting of Angelica sinensis during growth using UPLC-TOFMS and chemometrics data analysis. Chem Cent J 2013, 7:42-51. 
20. Iqbal M, Wani TA, Khalil NY, Darwish IA: Development and validation of ultra-performance liquid chromatographic method with tandem mass spectrometry for determination of lenalidomide in rabbit and human plasma. Chem Cent J 2013, 7:7-16.

21. Shang EX, Zhu ZH, Liu L, Tang YP, Duan JA: UPLC-QTOF-MS with chemical profiling approach for rapidly evaluating chemical consistency between traditional and dispensing granule decoctions of Tao-Hong-Si-Wu decoction. Chem Cent J 2012, 6:143-151.

22. Ghosh A, Mandal S, Banerji A, Kar M, Banerji J: A new chalcone from Pongamia pinnata and its antioxidant properties. Natural Product Communications 2009, 4:209-210.

doi:10.1186/1752-153X-7-126

Cite this article as: Fan et al: Determination of five flavonoids in different parts of Fordia cauliflora by ultra performance liquid chromatography/triple-quadrupole mass spectrometry and chemical comparison with the root of Millettia pulchra var. laxior. Chemistry Central Journal 2013 7:126

\section{Publish with ChemistryCentral and every scientist can read your work free of charge \\ "Open access provides opportunities to our colleagues in other parts of the globe, by allowing anyone to view the content free of charge." \\ W. Jeffery Hurst, The Hershey Company. \\ - available free of charge to the entire scientific community \\ - peer reviewed and published immediately upon acceptance \\ - cited in PubMed and archived on PubMed Central \\ - yours - you keep the copyright \\ Submit your manuscript here: \\ http://www.chemistrycentral.com/manuscript/<smiles>c1ccccc1</smiles> 